\title{
In vitro models of the human blood-brain barrier and the impact of efflux transporters on neurological disorders: the work of Cioni et al. (2012)
}

\author{
Silke Vogelgesang ${ }^{1 *}$ and Gabriele Jedlitschky ${ }^{2}$ \\ 1 Department of Neuropathology, Institute of Pathology, University of Greifswald, Greifswald, Germany \\ ${ }^{2}$ Department of Pharmacology, Center of Drug Absorption and Transport (C_DAT), University of Greifswald, Greifswald, Germany \\ ${ }^{*}$ Correspondence: sivogelg@uni-greifswald.de \\ Edited by: \\ Barry Boland, University College Cork, Ireland \\ Reviewed by: \\ Barry Boland, University College Cork, Ireland \\ Shane V. Hegarty, University College Cork, Ireland
}

Keywords: blood-brain barrier, P-glycoprotein, St. John's wort, Alzheimer's disease

\section{A commentary on}

Expression of tight junction and drug efflux transporter proteins in an in vitro model of human blood-brain barrier

Cioni C, Turlizzi E, Zanelli U, Oliveri G, Annunziata P. Front Psychiatry (2012) 3:47. doi: 10.3389/fpsyt.2012.00047

The blood-brain barrier (BBB) plays a fundamental role in the integrity of brain homeostasis. Acute disruption and also even slight shifting of equilibrium of structural elements or transport processes might lead to substantial consequences, resulting in neurological disorders (1).

There is a fundamental need for the development and improvement of in vitro models of the BBB in order to understand the biology of these important regulatory tissues, and also to target the BBB in new approaches to the treatment of neurological diseases such as Alzheimer's disease (AD), stroke, and Parkinson's disease (2). Capillaries were first successfully isolated from the rat brain in 1973 (3). Since then, a number of in vitro models have been developed that are based on primary endothelial cells isolated from several species, the most widely used being rodent, porcine, or bovine cells (4), or on immortalized human brain endothelial cell lines such as hCMEC/D3 cells (5). These monoculture systems, however, are a rather simplified in vitro model in that the interactions of endothelial cells with neighboring cells of the neurovascular unit, namely, astrocytes and pericytes, are important for the development and maintenance of BBB properties $(1,6)$. A fundamental characteristic of the BBB is the formation of interendothelial tight junctions, which is indicated by high transendothelial electrical resistance (TEER) values and the expression of representative tight junction proteins such as occludin (7). Furthermore, a broad range of membrane transporters are expressed at the BBB. ATP-bindingcassette (ABC) efflux transporters such as P-glycoprotein (P-gp, ABCB1) have been identified as key elements of the $\mathrm{BBB}$ that prevent many drugs and neurotoxic substances from entering the brain and that transport toxic metabolites out of the brain $(2,8)$. Astrocytes are important not only for the development of tight junctions but also for the up-regulation of efflux transporters such as P-gp (9). The most widely used in vitro models are based on nonhuman mammalian cells. However, there are species differences in expression levels, substrate affinities, and the regulation of relevant transporters (10). Especially for investigating BBB alterations in the pathogenesis of neurological diseases, the model should mimic the characteristics of the adult human BBB as closely as possible. On the other hand, the model should be reasonable in terms of cost, efficiency, and technical requirements.

Cioni et al. have developed a unique double compartment-model of the BBB consisting of cerebral endothelial cells isolated from cryopreserved human glial tumors. The endothelial cells are isolated together with astroglial cells from the same specimens. Special emphasis was placed by the authors on the activity of drug efflux transporters such as P-gp and members of the multidrug resistance protein- (MRP, ABCC) family, as well as solute carrier (SLC)-type transporters such as organic anion-transporting polypeptides (OATPs). Cioni et al. demonstrated that this brain endothelium culture system mimics a physiologically relevant situation, and may therefore provide a new tool for studying the effects of biological fluids or modulating substances at the BBB. A major advantage of this system is the use of cryopreserved material, which enables the collection of sufficient human brain endothelial cells for investigation (11).

The role of the ABC transporters in the pathogenesis of neurodegenerative disorders such as AD has been increasingly wellestablished in recent years. P-gp actively transports the amyloid- $\beta$ (A $\beta)$ peptides $A \beta 1-40$ and $A \beta 1-42$, which represent two of the most prevalent forms of the peptide in senile plaques and cerebral $A \beta$ angiopathy in the AD brain $(12,13)$. A decrease in P-gp expression has been found in the brains of non-demented aged humans, and low P-gp expression was associated with an increase in cerebral $\mathrm{A} \beta$ load $(14,15)$. It was therefore proposed that induction of P-gp function could restore the clearance of $A \beta$ peptides from the brain to blood via the BBB (16). Furthermore, animal models of $\mathrm{AD}$ have been used to investigate the effects of pharmacological P-gp modulation. Because of its known P-gpinducing effects, one potential candidate 
has been St. John's wort (SJW). Brenn et al. showed that mice receiving SJW extract showed significant reductions of parenchymal $A \beta 1-40$ and 1-42 accumulation, and significant increases in cerebrovascular Pgp expression (17). Furthermore, studies have revealed that specific SJW extracts both attenuate $A \beta$-induced histopathologic changes and alleviate memory impairments in APP-transgenic mice. Interestingly, these effects are independent of hyperforin in the SJW, suggesting that other components of SJW might be involved in its beneficial effects (18). In any case, these studies show that the induction of $\mathrm{ABC}$ transporters such as P-gp may be a novel therapeutic strategy to protect the brain from $A \beta$ accumulation, and thus, could impede the progression of neurologic diseases such as $\mathrm{AD}$.

In vitro models such as that described by Cioni and colleagues may help to reveal the underlying mechanisms by which BBB transporters influence pathogenic processes, and thus, could point the way toward more effective therapies in humans.

\section{REFERENCES}

1. Abbott NJ, Rönnbäck L, Hansson E. Astrocyteendothelial interactions at the blood-brain barrier. Nat Rev Neurosci (2006) 7:41-53. doi:10.1038/ nrn 1824

2. Jedlitschky G, Grube M, Mosyagin I, Kroemer HK, Vogelgesang S. Targeting CNS transporters for treatment of neurodegenerative diseases. Curr Pharm Des (2014) 20:1523-33. doi:10. 2174/13816128113199990460

3. Joo F, Karnushina I. A procedure for the isolation of capillaries from rat brain. Cytobios (1973) 8:41-8.

4. Cecchelli R, Dehouck B, Descamps L, Fenart L, Buee-Scherrer V, Duhem C, et al. In vitro model for evaluating drug transport across the blood-brain barrier. Adv Drug Deliv Rev (1999) 36:165-78. doi:10.1016/S0169-409X(98)00083-0
5. Weksler BB, Subileau EA, Perriere N, Charneau $\mathrm{P}$, Holloway $\mathrm{K}$, Leveque $\mathrm{M}$, et al. Blood-brain barrier-specific properties of a human adult brain endothelial cell line. FASEB J (2005) 19:1872-4. doi:10.1096/fj.04-3458fje

6. Nakagawa S, Deli MA, Nakao S, Honda M, Hayashi K, Nakaoke R, et al. Pericytes from brain microvessels strengthen the barrier integrity in primary cultures of rat brain endothelial cells. Cell $\mathrm{Mol} \mathrm{Neu}$ robiol (2007) 27:687-94. doi:10.1007/s10571-0079195-4

7. Cummins PM. Occludin: one protein, many forms. Mol Cell Biol (2012) 32:242-50. doi:10.1128/MCB. 06029-11

8. Shen S, Zhang W. ABC transporters and drug efflux at the blood-brain barrier. Rev Neurosci (2010) 21:29-53. doi:10.1515/REVNEURO.2010. 21.1.29

9. Gaillard PJ, van der Sandt IC, Voorwinden LH, Vu D, Nielsen JL, de Boer AG, et al. Astrocytes increase the functional expression of P-glycoprotein in an in vitro model of the blood-brain barrier Pharm Res (2000) 17:1198-205. doi:10.1023/A: 1026406528530

10. Deo AK, Theil FP, Nicolas JM. Confounding parameters in preclinical assessment of blood-brain barrier permeation: an overview with emphasis on species differences and effect of disease states. Mol Pharm (2013) 10:1581-95. doi:10.1021/ mp300570z

11. Cioni C, Turlizzi E, Zanelli U, Oliveri G, Annunziata P. Expression of tight junction and drug efflux transporter proteins in an in vitro model of human blood-brain barrier. Front Psychiatry (2012) 3:47. doi:10.3389/fpsyt.2012.00047

12. Lam FC, Liu R, Lu P, Shapiro AB, Renoir JM, Sharom FJ, et al. Beta-amyloid efflux mediated by p-glycoprotein. J Neurochem (2001) 76:1121-8. doi:10.1046/j.1471-4159.2001.00113.x

13. Kuhnke D, Jedlitschky G, Grube M, Krohn M, Jucker M, Mosyagin I, et al. MDR1-P-glycoprotein (ABCB1) mediates transport of Alzheimer's amyloid-beta peptides - implications for the mechanisms of Abeta clearance at the blood-brain barrier. Brain Pathol (2007) 17:347-53. doi:10. 1111/j.1750-3639.2007.00075.x

14. Vogelgesang S, Cascorbi I, Schroeder E, Pahnke J, Kroemer HK, Siegmund W, et al. Deposition of Alzheimer's beta-amyloid is inversely correlated with P-glycoprotein expression in the brains of elderly non-demented humans.
Pharmacogenetics (2012) 12:535-41. doi:10.1097/ 00008571-200210000-00005

15. Vogelgesang S, Warzok RW, Cascorbi I, KunertKeil C, Schroeder E, Kroemer HK, et al. The role of P-glycoprotein in cerebral amyloid angiopathy; implications for the early pathogenesis of Alzheimer's disease. Curr Alzheimer Res (2004) 1:121-5. doi:10.2174/1567205043332225

16. Hartz AM, Miller DS, Bauer B. Restoring blood-brain barrier P-glycoprotein reduces brain amyloid-beta in a mouse model of Alzheimer's disease. Mol Pharmacol (2010) 77:715-23. doi:10. 1124/mol.109.061754

17. Brenn A, Grube M, Jedlitschky G, Fischer A, Strohmeier B, Eiden M, et al. St. John's wort reduces beta-amyloid accumulation in a double transgenic Alzheimer's disease mouse model-role of P-glycoprotein. Brain Pathol (2014) 24:18-24. doi:10.1111/bpa.12069

18. Hofrichter J, Krohn M, Schumacher T, Lange C, Feistel B, Walbroel B, et al. Reduced Alzheimer's disease pathology by St. John's wort treatment is independent of hyperforin and facilitated by ABCC1 and microglia activation in mice. Curr Alzheimer Res (2013) 10:1057-69. doi:10.2174/ 15672050113106660171

Conflict of Interest Statement: The authors declare that the research was conducted in the absence of any commercial or financial relationships that could be construed as a potential conflict of interest.

Received: 18 June 2014; accepted: 29 August 2014; published online: 16 September 2014.

Citation: Vogelgesang S and Jedlitschky G (2014) In vitro models of the human blood-brain barrier and the impact of efflux transporters on neurological disorders: the work of Cioni et al. (2012). Front. Psychiatry 5:128. doi: 10.3389/fpsyt.2014.00128

This article was submitted to the journal Frontiers in Psychiatry.

Copyright (c) 2014 Vogelgesang and Jedlitschky. This is an open-access article distributed under the terms of the Creative Commons Attribution License (CC BY). The use, distribution or reproduction in other forums is permitted, provided the original author(s) or licensor are credited and that the original publication in this journal is cited, in accordance with accepted academic practice. No use, distribution or reproduction is permitted which does not comply with these terms. 